\title{
Local Perceptions of Environmental Changes and Adaptation Measure Implication on Coastal Community's Livelihood in Bagamoyo, Tanzania
}

\author{
Brown Gwambene and Ernest Karata \\ Faculty of Social Sciences and Entrepreneurship, Marian University College, P.O. Box 47, Bagamoyo, Tanzania \\ Email: gwambene@gmail.com, restkika@gmail.com
}

\begin{abstract}
The perceived and experienced environmental changes, decline in production of most livelihood activities resulted in divergence, whereas poor people are particularly vulnerable. The success of local community adaptation opinions, building resilience and improving adaptation capacity strongly influenced by perceptions. Through the household survey, key informant interviews and field observation; the study revealed the risk posed by changing environment to livelihood activities and the environment. Population increase, changing environment, poor access/lacking support for the livelihood development compounded by climate variability resulted in destruction of coastal resources. The effectiveness of adaptation measure at local communities halt dubious. Therefore, enhancing adaptation capacity, flexible livelihood activities and providing technical assistance to local adaptation options were recommended. Such measures include strengthening and capacitating community legal entities and key stakeholders in advocating effective local adaptation, stimulating engagement in alternative co-benefiting livelihoods that promote conservation and strengthen community aptitude.
\end{abstract}

Keywords: Environment change, local livelihood, coastal areas and sustainability

\section{Introduction}

The perceived environmental changes and the experienced decline in marine production is alarming along coast areas. The local community's livelihood activities resulted in growing divergence, whereas poor people are particularly vulnerable. The observed coastal and shoreline changes, eroded beaches, destructed fish haunts and shifted shorelines affects the beautiful scenery, disfigure beaches, fish catches, coastal forest and related livelihood activities [1]. Most of the people around Bagamoyo whose activities were built in Marine and commercial activities resulted from marine products have witnessed tremendous changes as mentioned above which lead to poor Coastal Community's Livelihood and dependence increasing among people in this society. The impacts of changing environment pose danger to livelihoods, social assets and the natural environment [2].

The local community along the coastal areas are adapting to the impact of the changing environment and climate variability. Previously, the main economic activity was fishing and local trade involving fish and fish products. Currently, due to the impact of changing environment the society is now adapting to various economic activities such as agriculture, carpentry, business, welding, livestock keeping and so on.

The success in building resilience and improving adaptation capacity among communities in Bagamoyo coast is strongly influenced by perceptions of the impacts that are experienced by local communities and opinions of adaptation strategies. However, the joint efforts of both the Government and other key stakeholders have increased awareness and catalyzed the whole process of adoption and changed the perception of the local community [2]. With the increasing population and awareness, the local community is not only depending on other activities, but also investing in education for diversity especially for the forthcoming generation. This shows that the local community along the coastal areas are adapting to the impact of the changing environment and climate variability. However, the effectiveness of adaptation measure that also has a broad array of positive and negative impacts on local communities halt dubious.

Positively, the Government and NGO's intervention helped to provide education and skills in the better ways of harvesting marine products, but negatively there is a slow implementation of 
scientific/technological methods of preventing eroded beaches, destructed fish haunts and shifted shorelines. Despite of good policies and laws like the Agriculture Policy (2013) which states that "... At the sector level, agriculture policies and programs tend to recognise climate change as important issue, and propose strategic objectives and activities that could support mitigation and adaptation activities in the sector" [3]. The community has never witnessed the actual implementation which could mitigate an on ongoing destruction taking place along the Bagamoyo beach. Nevertheless, the perception of the local community on environmental changes depends not only on other stakeholders but the Government at large. The mere recognition and policy making need to be translated promptly and changes must be seen. The policy emphasizes on the importance of competitive markets, with the Government providing priority to public goods and services and the conservation of environment as a rational basis for agricultural development. Furthermore, holistic development and local community adaptation go together with Agriculture Climate Resilience Plan (2014-2019) which recognize that irrigation alone will not be sufficient to adapt to climate change, and can indirectly drive vulnerability if water resources are not well managed [3]. Adaptation measures for improved water, soil and land management are urgently needed to build resilience to current variability and future climate change by both smallholders and commercial farms. Smallholder farmers are among the most vulnerable to even small variations in the climate, with major impacts on livelihoods and food security. Therefore, ensuring household livelihood, alternative sources of income and food security is one among the challenges facing the coastal community which need urgent solution.

\section{$2 \quad$ Methodology}

\subsection{Study Area}

This study was carried out in two streets (Dunda and Kaole) of the Bagamoyo District in the Coast Region of Tanzania with the overall purpose of establishing the local perceptions of environmental changes and implication of adaptation measure on local livelihood. Bagamoyo District is among the six districts in Coastal Region (Pwani) located in the western part of the Indian Ocean. The district lies between Latitudes 6o' and 7o south, and Longitudes 37o and 39o East with an altitude ranging from 0 to 100 meters above sea level (masl) [4] as indicated in Figure 1. The district bordered by the Tanga region to the North, Morogoro region to the west, the Indian Ocean to the East and Kinondoni and Kibaha districts to the South [5]. The ocean is rich in marine and coastal resources that sustain local cultural and social economic activities. The local livelihoods include artisanal fishing, mariculture, agriculture and livestock keeping, salt production and tourism. Extraction of mangrove, aquatic and coral resources also provide an important source of livelihood. The influx of people influenced the culture and social relations trigger a change of environment, economic disparities and diversification.

\subsection{Data Collection Methods and Tools}

Both secondary and primary data were collected. The secondary data was collected from different sources via internet search, the Marian University Collage libraries, public records and statistics were also included. Primary data were collected through household questionnaire surveys, key informant interviews and field observation. The questionnaire was developed to collect the data at the household level, whereas the key informant checklist used for interviews with key informant. The main information collected includes socio - economic, livelihood activities and the perceived environmental changes. Furthermore, adaptation measures, adaptive capacity, effectiveness of the local adaptation measures and the perceived options for improvement were obtained. Data collected through field observation complemented other data collection sources and method.

\subsection{Data Analysis}

The study used content analysis for the qualitative data, Statistical Package for Social Science (SPSS) and Microsoft excel for quantitative data analysis. Qualitative data from interviews with key informant and observation was extracted through content analysis. The content analysis used to organize the 
collected data according to categories and coding data for data entry in the Statistical Package for Social Science (SPSS) for quantitative analysis. The data were organized under relevant sub-headings to present the information from respondents for easy comprehension. The Quantitative data from questionnaires and documentary review were also analyzed using Statistical Package for Social Science (SPSS) and Microsoft Excel. The analyzed data presented in tables with frequencies, and percentages and in graphs were used for inferential conclusion.

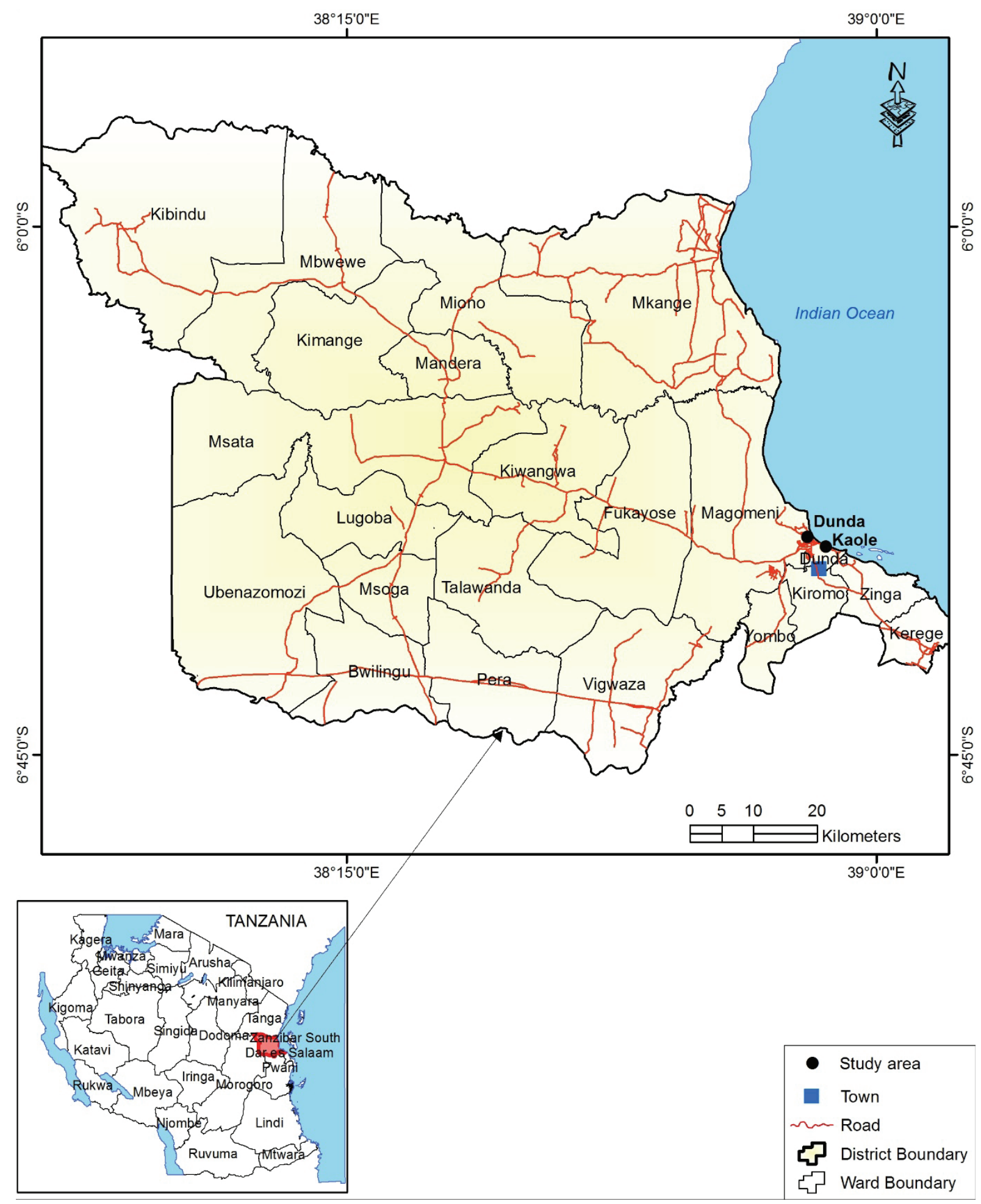

Figure 1. Map of Bagamoyo indicating the location of the study area 


\section{$3 \quad$ Results and Discussion}

\subsection{Main Livelihood Activities in the Area}

The study finding indicates that fishing, agriculture and fish business are the main livelihood activities as indicated in Table 1. This livelihood characterized by low production and use of poor technology, for example, the dominant artisanal fishing mainly conducted in the very shallow waters. Mkama et al [2] described the main economic activities in Bagamoyo district that include small holder farming, artisanal fishing, livestock keeping, mariculture (sea weed and prawn farming), salt production, trade, and tourism. Due to the changing environment, some of these activities are adversely affected.

Table 1. Local livelihood activities

\begin{tabular}{cccc}
\hline Main livelihood activities & N & Percent & Percent of Cases \\
\hline Fishing & 33 & 17.5 & 91.7 \\
Agriculture & 33 & 17.5 & 91.7 \\
Business & 30 & 15.9 & 83.3 \\
Fish business & 33 & 17.5 & 91.7 \\
Casual labour & 21 & 11.1 & 58.3 \\
Tourism craft & 21 & 11.1 & 58.3 \\
Tailoring & 18 & 9.5 & 50.0 \\
\hline Total & $\mathbf{1 8 9}$ & $\mathbf{1 0 0 . 0}$ & $\mathbf{5 2 5 . 0}$ \\
\hline
\end{tabular}

The main livelihood activities in the study area as indicated in Table 1 are Agriculture (91.7), Fishing (91.7) and Fish business (91.7). Other activities include Business (83.3), Casual labour (58.3), Tourism craft (58.3) and Tailoring (50.0). Crop production and livestock keeping are the major agricultural activities in the coastal areas of Tanzania [6] which are mainly subsistence with low value crops. Small fisherman characterizes the fishing activities in the area this includes the use of traditional methods and poor fishing gear. Tourism activities complement other economic sectors such as business sector, infrastructures, fishing, employment and agricultural sector [7].

\subsection{Local Community Awareness of Environmental Change}

The awareness of respondents on the environmental change was slightly good as most of them observed changes on their livelihood and environment in general. The perception of local community toward environment change and their implication on their livelihood was slightly higher on adverse effects. Figure 2 showed the knowledge and understanding of environmental changes. The result of analysis showed that $67 \%$ understand and have knowledge of the environment change, whereas $83 \%$ of respondents perceived changes in the environment.

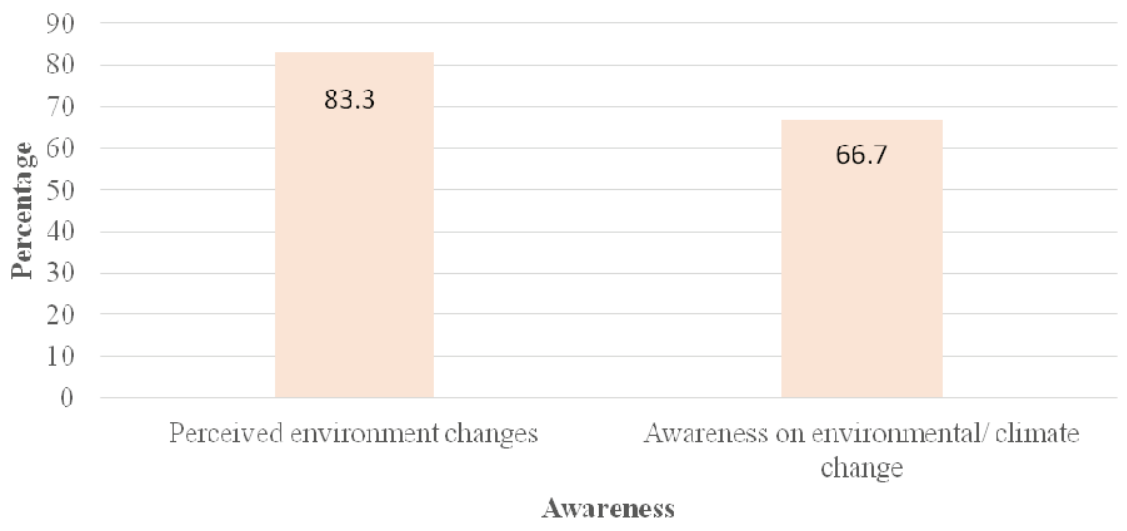

Figure 2. Local perceptions / awareness of environmental change 
The analysis of the results in Figure 2 indicates good awareness on the environment/ climate changes where $66.7 \%$ of the respondents said they are aware. Moreover, $83.3 \%$ were already feeling the changes through perceived impacts on their livelihood and environment resources. Such results show that local people in the two study villages are aware and understand the impacts of environment/ climate change in their livelihood. In case of the observed changes, the results indicate their understanding in different ways, depending on their experience, age and literacy level. The most beamed changes in climate were raising temperature and unpredictable rains that results in floods or droughts. They are also aware of occurrence of strong winds and the disappearance of some flora and fauna. Table 2 below shows the environment change as perceived by local community along the coastal area.

Table 2. The perceived environmental changes along the coastal area

\begin{tabular}{cccc}
\hline Environmental change & N & Percent & Percent of cases \\
\hline Increase of temperature & 9 & 21.4 & 27.3 \\
Fluctuating Rainfall & 9 & 21.4 & 27.3 \\
Strong wind & 3 & 7.1 & 9.1 \\
Soil erosion & 3 & 7.1 & 9.1 \\
Destruction of mangrove & 3 & 7.1 & 9.1 \\
Destruction of beaches & 3 & 7.1 & 9.1 \\
Loss of natural vegetation & 3 & 7.1 & 9.1 \\
*Decline in fish catch (an effect) & 6 & 14.3 & 18.2 \\
*Unregulated Fishing (an effect) & 3 & 7.1 & 9.1 \\
\hline Total & $\mathbf{4 2}$ & $\mathbf{1 0 0 . 0}$ & $\mathbf{1 2 7 . 3}$ \\
\hline
\end{tabular}

Through years local community observed changes in their environment and through experience they understand the changes and their subsequent effect on their livelihood. Among the observed changes in the study area include the fluctuating rainfall (27.3), increase of temperature (27.3) and loss of natural vegetation (9.1). Other environmental changes mentioned are destruction of beaches (9.1), destruction of mangrove (9.1), Strong wind (9.1) and Soil erosion (9.1) whereas, decline in fish catch (18.2) and unregulated fishing (9.1) are the resulting effects of the changing environment. Seaweed farming and salt making also increased deforestation of mangrove forest. Kamaruddin et al [8] argued that we become aware of our environment by processing a variety of input or be conscious of all the information we are exposed to at the moment. The information provided by local community indicates their level of awareness on the environment and management strategies. In the context of environmental management, awareness is highly influenced by various internal and external factors and advocated as the initial stage of the learning process [8]. The most important is having a basic understanding of the environment and its problems, championing the spirit of feelings of concern for the environment and participate in environmental improvement [8]; [7]; [9]. Thus, local community awareness and their perception are important aspect in environmental management programs and project initiatives.

\subsection{The Perceived Effects of Environmental Changes on Local Community}

Environment change affects local communities in the coastal area through modification or changing their livelihood. The result of this study indicates awareness of the local community on the effect of environmental change on their livelihood and environment at large. Negative effects are most pronounced by the local community as indicated in Table 3 below. This may be due to low adaptive capacity to harness the opportunities that may accrue from the changing environment. In addition, most local community in less developed country tends to focus on negative effects as it affects them the most.

Table 3 indicates that decrease of fish catches (90) has been severely affected by the environmental change. This is due to the fact that most local community along the cost depend much on fishing activities for their livelihood. The other revealed effects on livelihood include decrease of crop production (70), Fluctuation of business opportunities (70) and Decrease income (70). Such effect exerted on other effects such as eroded/disfigure beaches (50), high price for fish (50), increase destructive fishing (30), decrease income (10) and illegal fishing (10). All these effects affect the community livelihood. 
Table 3. The effects of environment on local community livelihood

\begin{tabular}{cccc}
\hline Effect of environment change & N & Percent & Percent of cases \\
\hline Decrease of fish catches & 27 & 19.6 & 90.0 \\
Decrease of crop production & 21 & 15.2 & 70.0 \\
Fluctuation of business opportunities & 21 & 15.2 & 70.0 \\
Decrease income & 21 & 15.2 & 70.0 \\
Increase destructive fishing & 9 & 6.5 & 30.0 \\
Eroded/ Disfigure beaches, & 15 & 10.9 & 50.0 \\
High price for fish & 15 & 10.9 & 50.0 \\
Shortage of fish & 3 & 2.2 & 10.0 \\
Decrease of income & 3 & 2.2 & 10.0 \\
Illegals fishing & 3 & 2.2 & 10.0 \\
\hline Total & $\mathbf{1 3 8}$ & $\mathbf{1 0 0 . 0}$ & $\mathbf{4 6 0 . 0}$
\end{tabular}

Both direct and indirect impacts of environmental change have resulted into decreasing crop production, fish catch and negatively impacted other local livelihood. Such situation increased vulnerability and food insecurity among the local community as food security in the study area is directly proportional to fish catch and agricultural production. Thus, any deficit in catch and harvesting means inadequate food and low income for households. The results revealed that local community is at risk due to changing environment as indicated by $85 \%$ of respondents. Another vulnerable group to changes include the Government $(57 \%)$ because it will lose income, local farmers (28\%) due to loss of harvest and the Fisherman (14\%) as a result of decline in fish catch. Such results are also discussed in other literature [1]; [10]; [11]; [6]. Figure 3 indicates the most vulnerable group to a changing environment.

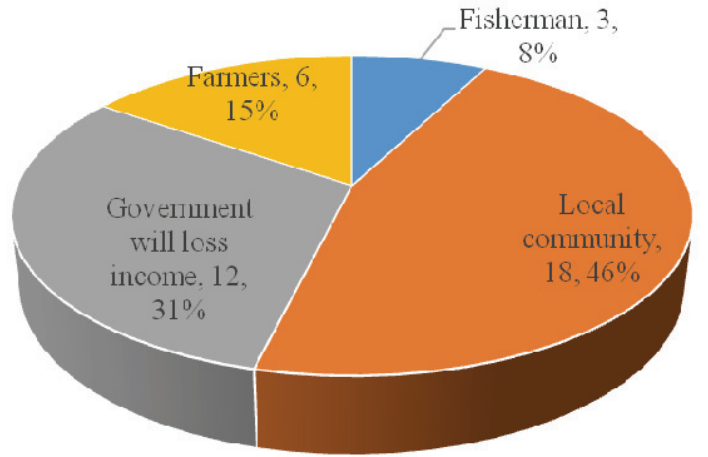

Figure 3. The most vulnerable group

The results in Figure 3 above indicate high vulnerability to local community (46\%) to a changing environment. This is due to low adaptive capacity and less available alternative livelihood. Such results also discussed by $[12 ; 13]$ whereby the local community especially, smallholder farmers and fishermen are shown as the most affected and have low adaptive capacity. Also they are vulnerable due to their dependence on the fluctuating parameter and changing environment. The Government also indicated as a vulnerable group through losing their income buy loss of revenue and using much of revenue in relief and reconstructions of affected and protection infrastructure. Understanding coastal communities' vulnerabilities and their perceived adaptation measures provides guidance for planning for management strategies [2] and improving livelihood reducing vulnerability and enhancing resilience among the local communities.

\subsection{The Perceived Local Adaptation Measures}

Local community developed multi-activity livelihood strategies to survive during stress that help them to earn income and food security. Such activities constitute the basis of a diversified livelihood strategy 
upon which households rely and reduce vulnerability through spread of risks between various economic activities in an uncertain environment and generate cash when other household activities offer little potentials. Figure 4 indicates the local adaptation measures to the changing environment along the coastal areas.

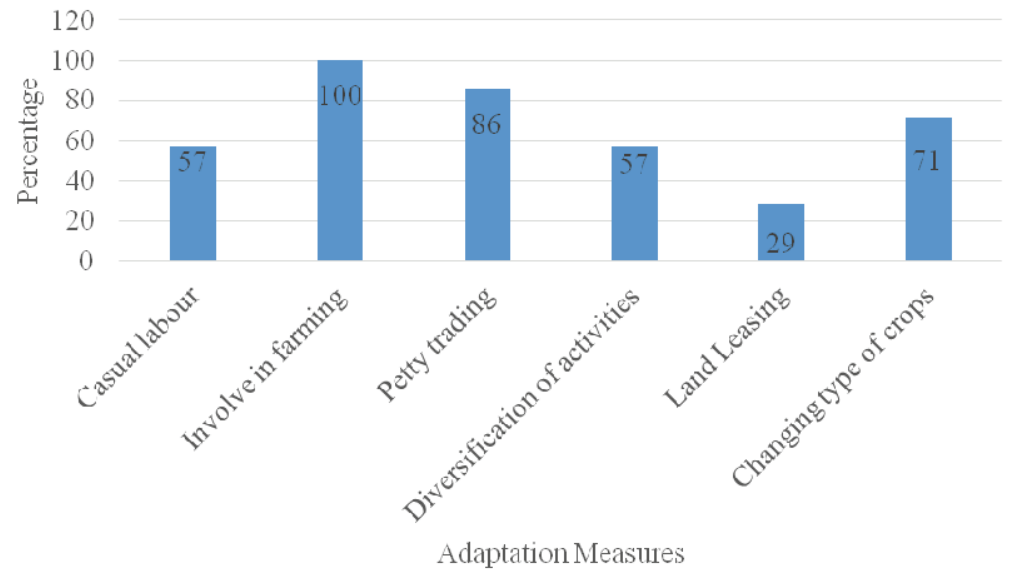

Figure 4. Adaptation measure to changing environment among the local coastal community

Fishing is the mainstay livelihood activity along the coastal area community followed by agriculture. Figure 4 indicates adaptation strategies to the changing environment. The results indicate that local community involvement in farming $(100 \%)$ as alternative activities to fishing. However, the two activities are most affected by the changing environment that forces the local community to develop or to engage in other alternative livelihood activities for their survival. The adaptation activities include casual labour (57\%), Petty trading (85\%), Diversification of activities (57\%), Leasing land (28\%) and changing the type of crops $(71 \%)$.

\subsection{Effectiveness of the Local Adaptation Measures}

Understanding the effectiveness and adequacy of adaptation measures is an important aspect in enhancing livelihood resiliency and improving environmental resources management. Local community developed a number of adaptation measures to enhance livelihood and environment management. Such measures to some extent help them to survive during the hardship as indicated in Table 4 below. Assessment of effectiveness of such measures is inevitable due to the nature of adaptation measures that varies with objectives in address existing challenges and explicitly with a consideration of livelihood and environment risks. The effective implementation can be enhanced through integrated responses that link mitigation and adaptation with other societal objectives $[14 ; 8]$. These include effective institutions and governance, innovation and investments in environmentally sound technologies and infrastructure, sustainable livelihoods and behaviour and lifestyle choices [8].

Table 4. Effectiveness of the method used in the adaptation

\begin{tabular}{cccc}
\hline Effectiveness of the method & N & Percent & Percent of cases \\
\hline Allocation of fishing area & 9 & 33.3 & 37.5 \\
Increase of income & 12 & 44.4 & 50.0 \\
Reduction of bush fire and tree planting & 3 & 11.1 & 12.5 \\
Lack of understanding of community & 3 & 11.1 & 12.5 \\
\hline Total & $\mathbf{2 7}$ & $\mathbf{1 0 0 . 0}$ & $\mathbf{1 1 2 . 5}$ \\
\hline
\end{tabular}

Through key informant interview, the results revealed that to some extent the adaptation measures helps local community to survive during the hardship situation caused by a changing environment. The results in Table 4 indicate the effectiveness of the adaptation measure to reduce impacts of 
environmental change. Increase of income (50.0) and allocation of fishing area (37.5) were mentioned as a result of adaptation measures to improve local livelihood and environment management. Other mention effectiveness of the adaptation measure was reduction of bush fire and tree planting (12.5). Lack of understanding of local community (12.5) was mentioned as a negative factor for the effectiveness of the measures used in copying and adaptation to adverse impact of environmental changes.

\subsection{Perception Option for Improving Local Livelihood and Environment Management}

The effects posed by environmental changes and climate variability to livelihoods, social assets and the natural environment are hard to extrapolate. It has both positive and negative impacts on local community livelihoods and environmental resources at large. Most of the respondents perceived negative impacts on fisheries and agricultural livelihoods resulted from increased population and changing environment. However, the most important part is to understand the development and suggested measures to ameliorate the situation to betterment of the community livelihood and their surroundings. Figure 5 below indicates the perceived measures for improving local livelihood and coastal management measures.

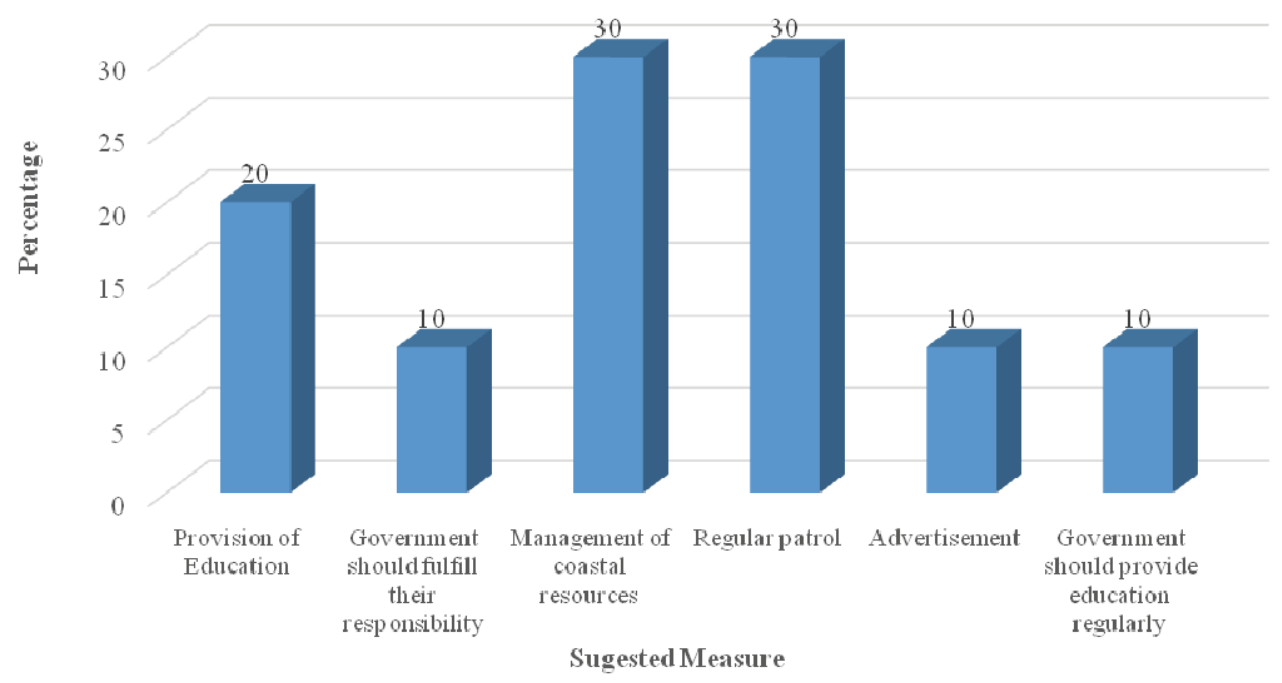

Figure 5. The perceived measures for coastal resource management measures

The result in Figure 5 shows that management of coastal resources (30\%), regular patrol (30\%), and provision of education (20\%) serve as important measures in improving livelihood and environmental management. Others include fulfillment of responsibility specifically, for the government (10\%), advertisement for the management strategies (10\%) and provision of regular education (10\%). The perceived measures indicate the need for the government institution to take their responsibility of organizing and governing. Thus, strengthening and capacitating community legal entities and key stakeholders in advocating climate change adaptation at the local level, stimulating the community engagement into alternative co-benefiting livelihoods that promote management strategies at the same time strengthening community aptitude. Table 5 shows the optional measures for improving livelihood and coastal resource management.

The results in Table 5 indicate that adherence and enforcement of by law (54.5) are the most suggested measures for improving livelihood and environmental management. Such results indicate the importance of adherence and enforcement of bylaws as it has affected them most. Other suggested measures for improvement of livelihood include awareness on climate change (18.2), empowerment of environmental resources conservation committee (9.1), Pre-license Inspection for driving (9.1) and Participatory management (9.1). The Participatory management needs to strengthen collaboration that would result in efficiency and improved adaptive measures to local livelihood and coastal resources management. 
Table 5. Optional measures for improving livelihood and coastal resources management

\begin{tabular}{cccc}
\hline Important measures & N & Percent & Percent of cases \\
\hline Awareness on climate change & 6 & 18.2 & 20.0 \\
Environment resources management committee & 3 & 9.1 & 10.0 \\
Adherence and enforcement of by -law & 18 & 54.5 & 60.0 \\
Pre-license Inspection for driving & 3 & 9.1 & 10.0 \\
Participatory management & 3 & 9.1 & 10.0 \\
\hline Total & $\mathbf{3 3}$ & $\mathbf{1 0 0 . 0}$ & $\mathbf{1 1 0 . 0}$ \\
\hline
\end{tabular}

Poor access to or lacking support for the development of livelihood assets compounded by environmental change resulted in destruction of livelihood activities. The communities that are highly dependent on environmental resources are most affected by such changes. Establishment of adaptation capacity building and facilitation of flexible livelihoods activities to enhance and provide technical assistance to local adaptation options was recommended. Furthermore, establishment of strategies for accessible and reliable markets for fish and produce is among the important option.

\section{Conclusions and Recommendations}

Adherence and enforcement of bylaws is among the most suggested factor for improving livelihood and coastal resource management. This will strengthen and capacitate community legal entities and key stakeholders in advocating adaptation and management strategies at the local level. Thus stimulating the community engagement into alternative co-benefiting livelihoods that promote management strategies and strengthening community aptitude.

Strategies for accessible and reliable markets for fish and produce was recommended in enhancing resilience at a local and national level. This needs to include strengthened collaboration for efficiency and improvement of adaptive measures to the local community and coastal resources management.

Need for strengthening and capacitating community legal entities and key stakeholders in advocating environmental management and climate change adaptation measures at the local level. This will need the local authorities and experts to stimulate alternative that meet a co-benefit livelihoods that promote conservation at the same time strengthening community aptitude. Such alternatives encompass an issue of storage, processing and packaging fish and produce for enhancing resilience and sustainability.

The scientific research and programs need to coalesce the local knowledge and perception in understanding and managing environmental resources for effectiveness and sustainability. This would entire raise awareness among the local community through incorporation of their local perceptions and knowledge in the formulation of the development agenda and encourage stakeholder participation. Thus, increase community participation in environmental management programs and increase environmental awareness and responsible.

\section{References}

1. Gwambene B, Karata E. (2019) Marine conservation: local community perceptions of coastal resources conservation and livelihood implication in Bagamoyo. Horticult Int J. 2019; 3(1):31-35. DOI: 10.15406/hij.2019.03.00108.

2. Mkama, W., Msuya S., Mahenge, J., Mposo. A, Jason, A.N., Amanzi, A., Chausiku. A., Kundengukila, F. (2013). Bagamoyo District Coastal Climate Change Rapid Vulnerability and Adaptive Capacity Assessment, Bagamoyo District, Tanzania. Coastal Resources Center, University of Rhode Island, Narragansett, RI, 26 pp.

3. United Republic of Tanzania [URT] (2014) Agriculture Climate Resilience Plan 2014-2019 Ministry of Agriculture, Food Security and Cooperatives. Dar es Salaam.

4. United Republic of Tanzania [URT] (2015). Coast Region Investment Profile. Prime Minister's Office, Regional Administration and Local Government. Pwani, Tanzania.

5. Bagamoyo District (2006). The Bagamoyo District Profile. Bagamoyo, Tanzania.

6. Majule A. E (2012). Implications of ecological and social characteristics to community livelihoods in the coastal areas of Tanzania. African Journal of Environmental Science and Technology Vol. 6(1), pp. 72-79. 
7. Massawe, D P (2013). Cultural tourism and livelihood of communities Along Indian Ocean in Tanzania: A case of Bagamoyo historical town. MBA- Dissertation, Mzumbe University; http://hdl.handle.net/11192/2043 (Accessed January 28, 2019).

8. Kamaruddin S M, Ahmad P, and Alwee N (2016) Community Awareness on Environmental Management through Local Agenda 21 (LA21). Procedia - Social and Behavioral Sciences 222 (2016) 729 - 737. Elsevier Ltd; http://creativecommons.org/licenses/by-nc-nd/4.0/ (Accessed January 30 2019).

9. Gwambene, B. (2018). Smallholder farmer's perspective to resilience: adaptation challenge in increasing crop production in the southern highlands of Tanzania, South Asian Journal of Development Research, 1(1): 1-8

10. Mbilinyi A, Saibul G.O and Kazi V (2013). Impact of climate change to small scale farmers: voices of Farmers in village communities in Tanzania. Economic and Social Research Foundation, ESRF Discussion Paper No. 47.http://preview.tinyurl.com/jp8rn4r (Accessed July 23, 2015).

11. Kristjanson P, Neufeldt H, Gassner A, Mango J, Kyazze B.K, Desta S, Sayula G, Thiede B, Forch W, Thornton P.K and Coe R (2012). Are food insecure smallholder households making changes in their farming practices? Evidence from East Africa. CCAFS World Agroforest Centre. Nairobi. Springer.

12. Gwambene B (2012). Land Utilization for Agriculture and Environment Management, Soil Management in Rungwe, Tanzania. Saarbrucken Deutschland. LAP LAMBERT Academic Publishing.

13. Kangalawe R (2012). Food security and health in the southern highlands of Tanzania: A multidisciplinary approach to evaluate the impact of climate change and other stress factors. African Journal of Environmental Science and Technology Vol. 6 (1), pp. 50-66, http://tinyurl.com/mszj2z3 (Accessed January 23, 2015).

14. Abe, N. and Didham, R. (2013). Measuring public awareness and actions for 3Rs Institute for Global Environmental Strategies. Ministry of the Environment of Japan (MOEJ) https://pub.iges.or.jp/pub_file/ 3r08pdf/download (Accessed January 30, 2019). 